\title{
The research on soft start and buck energy-saving simulation of
}

\section{asynchronous motor}

\author{
Zhang Bo ${ }^{1, a}$, Duan Minghao ${ }^{2, b^{*}}$, Yin Deyang ${ }^{1, c}$, Mo Huaqing ${ }^{2, d}$, \\ Zhang Chengyuan ${ }^{2, f}$ \\ ${ }^{1}$ College of Energy and Electrical Engineering, Hohai University Nanjing, Jiangsu \\ ${ }^{2}$ College of Internet of Things Engineering, Hohai University Changzhou, Jiangsu

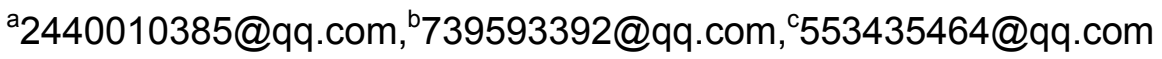

\begin{abstract}
Keywords: asynchronous motor, variable load, energy-saving, simulation
Abstract. In order to achieve the goals that asynchronous motor operates energy -savingly and economically by lowering the operating voltage when the light load or no-load running, this paper starts from the $\mathrm{T}$ simplified model of asynchronous motor, and analyzes the energy consumption in detail, then uses the basic principle of regulating technology from two-way thyristor to save energy, at last, it gets key factors affecting the stability of output voltage, that is power factor Angle fluctuations. Through the simulation and analysis of the energy-saving control system for asynchronous motor, it proves that when making soft start control to asynchronous motor and the trigger angle of thyristor starting in slope way. So the starting performance of the system are improves greatly. At the same time, the introduction of power factor angle to fuzzy self-tuning PID closed-loop control, the stability and reliability of the whole regulation process have improved significantly asynchronous motor operates energy -savingly and economically when the light load or no-load running.
\end{abstract}

\section{Introduction}

Overseas research in energy saving of motor is as early as in the domestic [1].Focuses on motor energy-saving designing [2] , advantages of permanent magnet motor has accumulated a wealth of experience in design and application. But the high price of permanent magnet motor, is difficult to promote in China. Because the lower price of squirrel-cage asynchronous Motors structure is simple, especially compared with permanent magnet motor, also has a price advantage, domestic application of squirrel-cage induction motors are very common, totally market $76.5 \%$ [3]. While domestic users on the motor type selection, in order to ensure the motors work reliably we always take measures the "big horse with small car", that is the motor power rating more than the rating of the load power, while motors are working at low efficiency, so many domestic manufacturers are starting of squirrel-cage induction motor energy-saving control in recent years began to study .

\section{Simplified model of asynchronous motor}

In order to study the induction motor in idling or light load, rate load and the starting instant of voltage, current, power factor and torque variables change, and find the right energy-saving solutions,so we start from the studying of the mathematical model of asynchronous motor. Fig. 1 is a simplified model of induction motor model T-model . 


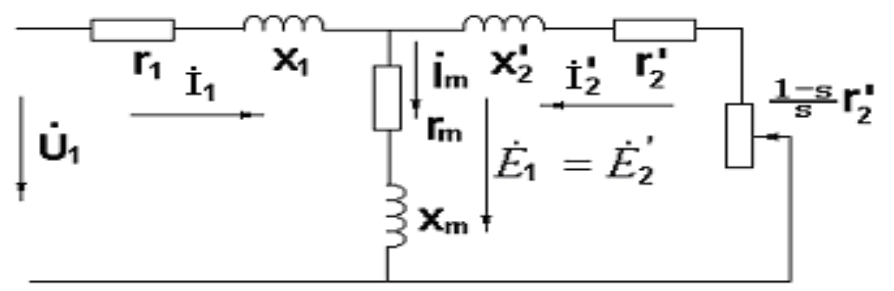

Fig.1 a simplified model of induction motor model T

In the electric circuit, ${ }^{r_{1}}$ and ${ }^{x_{1}}$ is stator winding resistance and leakage reactance; ${ }^{\prime}$ and ${ }^{x_{2}^{\prime}}$ is after checking the resistance of the rotor windings and leakage reactance; ${ }^{r_{m}}$ and ${ }^{x_{m}}$ are Corresponding to the electronics core loss resistance and corresponds to the main flux of excitation of core excitation magnetic reactance; $\dot{E}_{1}$ and $\dot{E}_{2}^{\prime}$ are Electromotive force of stator and rotor after the equivalent of electromotive force; $S$ is slip.

\section{Simulation analysis on energy-saving control system of asynchronous motor}

In order to intuitive module block diagram of building mathematical model system, so we use MATLAB Simulink to the system modeling and simulation.

Control system simulation

Building energy-saving controller of asynchronous motor system simulation model as shown in the Fig.2, which consists of Asynchronous motor, Three phase AC voltage source,Synchronization of 6 pulse trigger, Voltage thyristor module, The current of stator, The stator voltage detection module, Power factor angle detection module and Fuzzy self-tuning PID control module. Model of thyristor trigger circuit as shown in Fig.3.

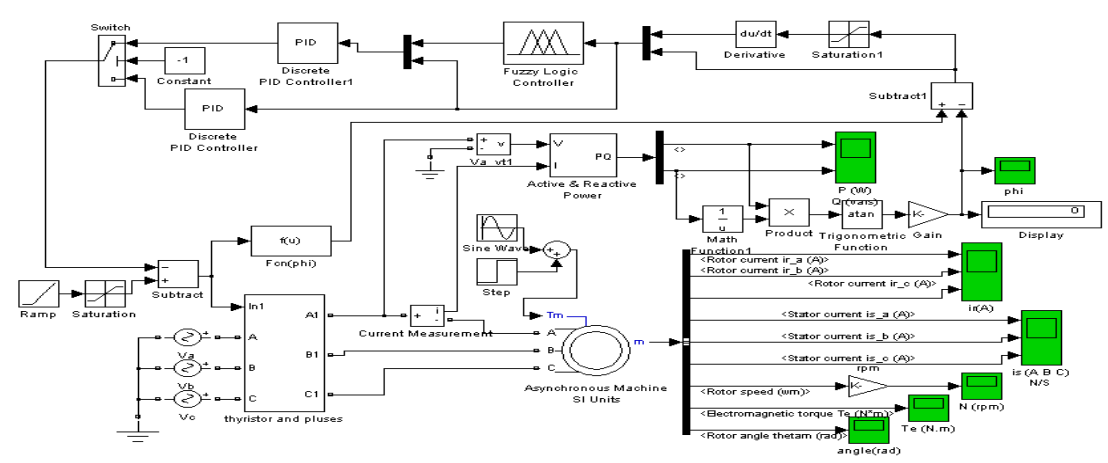

Fig.2 Efficient automatic energy-saving controller of asynchronous motor simulation schematic diagram

When starting motor at the corner of thyristor purposes in a slope way, motor stator voltage up slowly, driving torque of the motor also slowly improving. When the driving torque is bigger than the damping torque or load torque, the motor start to rotate, then it will achieve to stable operation. When Three-phase asynchronous motor direct starting, the starting current is bigger than the rated current 4 7 times. A phase stator current waveform is showned in the Fig.4, when motor direct starting. Model of motor rated current is 8.8A. Directly starting the maximum current up to about 5 times than the rated current; When the soft Starter control for asynchronous motor, in a slopes start mode, 
Starting current than the direct starting, reducing by nearly half, The starting energy is saving, Fig.5 is thyristor trigger angle slopes start mode, A phase stator current waveform.

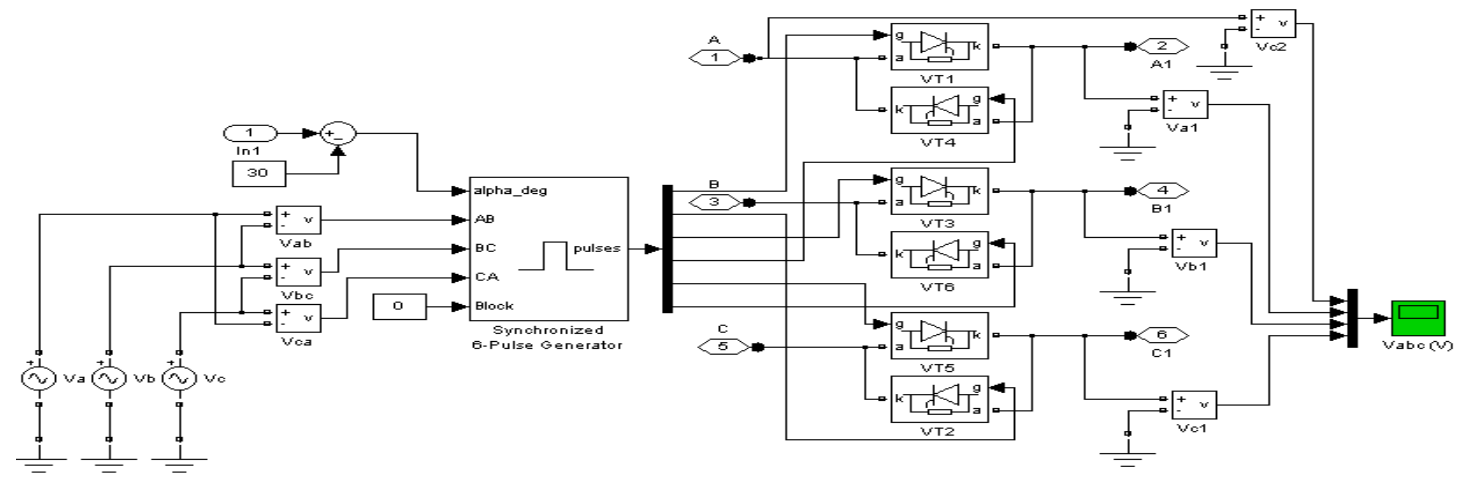

Fig.3 Model of thyristor trigger circuit

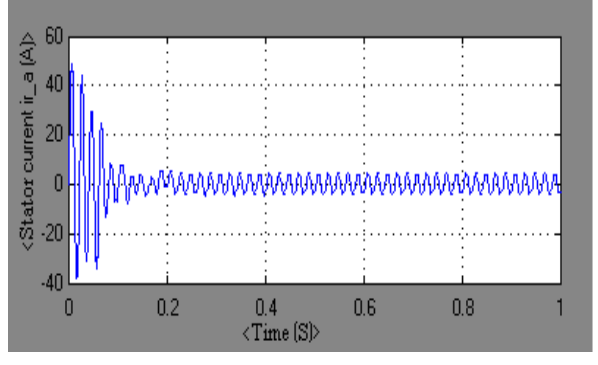

Fig.4 when motor direct starting, A phase stator current waveform

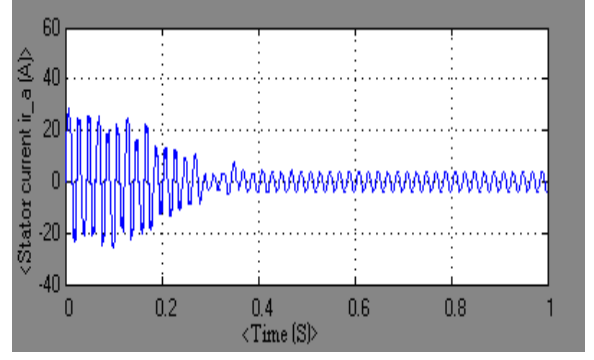

Fig.5 when thyristor trigger angle in a slopes start way, A phase stator current waveform

Simulation of closed-loop power factor angle control

Using Fuzzy Logic Toolbox MATLAB Simulink of fuzzy control in the Toolbox to design of a fuzzy self-tuning PID controller.Fig.6is A phase factor angle detection module. Fig. 7 is before PID control of phase A power factor of asynchronous motor changing waveforms.

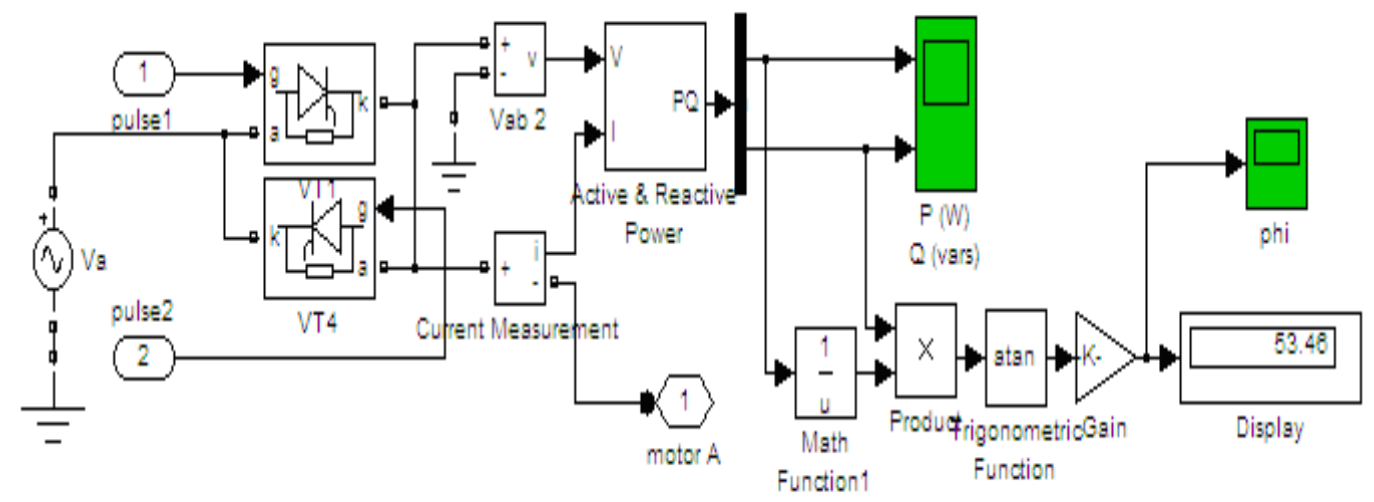

Fig. 6 A phase power factor angle detection module

After a traditional incremental PID control of power factor angle, if we break the load torque step change on the original disturbance, power factor angle will soon restore stability. Moreover it will not have big fluctuations. Fig. 8 is A phase power factor of asynchronous motor changed after a wave of traditional incremental PID control. 

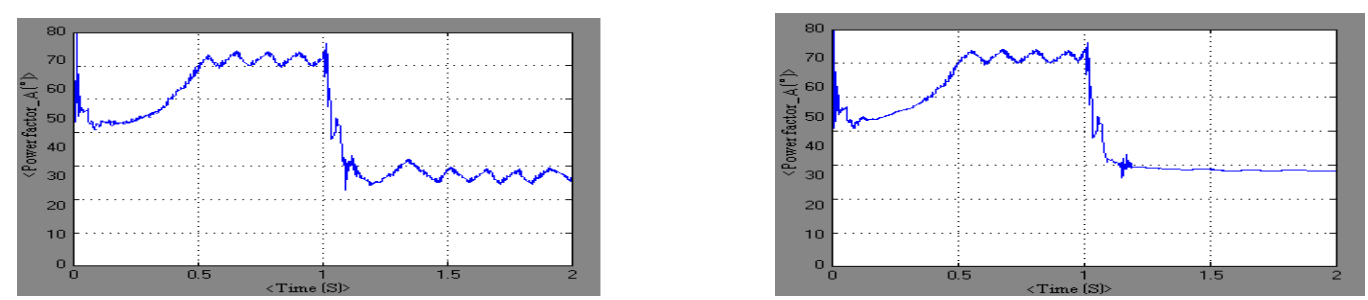

Fig.7 Before PID control of phase A power factor of asynchronous motor changing waveforms

Fig.8 A phase power factor of asynchronous motor changed after a wave of traditional incremental PID control.

After the fuzzy self-tuning PID control of the power factor angle, if we break the load torque step change on the original disturbance, power factor angle will soon restore stability. Power factor angle will not only be able to quickly restore stability,but also compared with traditional incremental PID control, it has a lot of advantages, such as speed regulation, small overshoot, and the stability is better,and don' t have fluctuation in basic. Fig.9 is after fuzzy self-tuning PID control, A phase power factor of asynchronous motor changing waveforms.

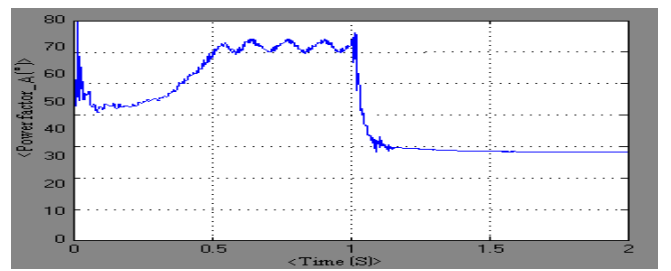

Fig.9 is after fuzzy self-tuning PID control, A phase power factor of asynchronous motor changing waveforms

After we conducte for the power factor of asynchronous motor fuzzy self-tuning PID control,it has better performance and robustness. For load fluctuation, it has a good adaptability,and has convenient adjustment and flexibility advantages.

\section{Thyristor conduction angle comparison test}

Thyristor conduction angle has closely related of narrow pulse triggering. When the firing angle increases, Thyristor after flow period is becoming shorter. When the trigger angle is increased to a certain extent, trigger of thyristor turn-on time will less than $60^{\circ}$. Disconnection will occur between the trigger pulse and the replacement pulse, which will make the output voltage and current fluctuations larger,and it is not conducive to stability of the system. So when reducing voltage and saving power voltage should not drop too low. Fig.10 is when triggering angle $\alpha=90^{\circ}$, MATLAB simulation of the A phase thyristor output waveforms and measured A phase thyristor conduction angle output waveforms. Fig. 11 is when triggering angle $\alpha=120^{\circ}$, MATLAB simulation of the A phase thyristor output waveforms and measured A phase thyristor conduction angle output waveforms. 

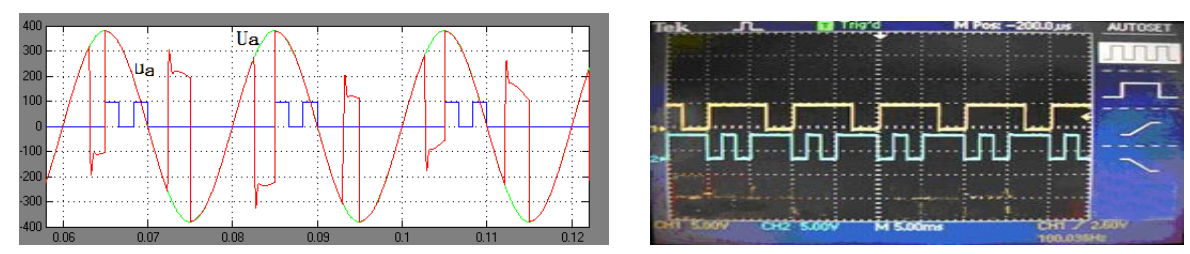

Fig.10 when triggering angle $\alpha=90^{\circ}$, MATLAB simulation of the A phase thyristor output waveforms and measured A phase thyristor conduction angle output waveforms
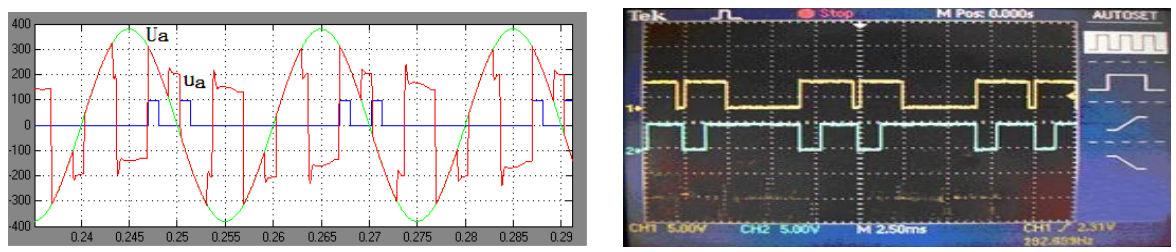

Fig.11 when triggering angle $\alpha=120^{\circ}$, MATLAB simulation of the A phase thyristor output waveforms and measured A phase thyristor conduction angle output waveforms Apparent from Fig.11, A phase thyristor conduction angle has dried up obviously. At that time, voltage fluctuation range big and it is not conducive to the stable operation of motor.Further evidence of the pressure energy-saving measures against that motor terminal voltage can not drop too low.

\section{Conclusion}

When energy saving controller of asynchronous motor in the process of adjusting the pressure, the load is not uniform and the grid voltage is imbalance, which will lead to the fluctuation of motor terminal voltage, and then result in the fluctuation of motor current. So we must introduce feedback.

In the process of adjusting the pressure, if the controller can keep the system power factor angle constant, then the thyristor voltage output to the motor voltage circuit will be constant, Current of motor will not be fluctuate, so the introduction of the closed loop control of the power factor angle can effectively inhibit the the fluctuation of motor current. Because of the the close relationship between the power factor angle and the thyristor trigger angle, So this controller prefer power factor angle as the system feedback control in the process of pressure.

\section{References:}

[1] J.Oyama, F.Profumo, E.Muljadi, T.A.Lipo. Design and Performance of a Digitallyb Based Voltage Controller for Correcting Phase Unbalance in Induction Machines[J]. IEEE Transactions on Industry Applications, 1990, 3(26):559-576.

[2] Timothy M.Rowan, Thomas A.Lipo. A Quantitative Analysis of Induction Motor Performance Improvement by SCR Voltage Control[J]. IEEE Transactions on Industry Applications, 1983,19(4):545-553.

[3] Aliev.1.1.Power Factor of Asynchronous Energy-saving Motor[J]. Russian Electrical Engineering,2004,5(75):42-44. 